\title{
Medical Students Perception About Implementation of Video-Assisted Blended Learning in Ophthalmology Clinical Clerkship During COVID-19 Pandemic Period
}

\author{
Hendriati $^{1}$ Muhammad Syauqie ${ }^{1, *}$ \\ ${ }^{l}$ Department of Ophthalmology, Faculty of Medicine, Andalas University, West Sumatra, Indonesia \\ ${ }^{*}$ Corresponding author. Email: m.syauqie@med.unand.ac.id
}

\begin{abstract}
The COVID-19 pandemic has disrupted teaching in a variety of institutions, especially in medical schools. Electronic learning (e-learning) became the core method of teaching the curriculum during the pandemic. This study explores the clerkship medical student's perspective toward the e-learning method during the COVID19 pandemic period in the Department of Ophthalmology of Faculty of Medicine Andalas University, Indonesia. The medical students enrolled in the iLearn online platform and completed the tasks assigned and fill the questionnaire to know their perception about e-learning. This study results show that most students agree that they can understand their learning objective through online learning. However, they also argue that the face-to-face method was more effective than online learning, especially in complicated clinical skills such as subjective refractive examination. This study results can encourage a blended learning model, which incorporates videoassisted online resources, which can be useful for acquiring clinical skills by medical students.
\end{abstract}

Keywords: medical education, online learning, blended learning, covid-19, iLearn

\section{INTRODUCTION}

Over the last six months, Covid-19 has relentlessly spread as a pandemic across the world, severely disrupting the world population's lives, especially within low and middle-income countries (LMIC). The major challenge of the COVID-19 pandemic to all countries, including LMIC, has been their healthcare systems. Before the COVID-19 pandemic in LMIC, there was already a combination of high population health demand and insufficient health workers numbers ${ }^{[1,2]}$.

Medical education throughout the world has experienced significant changes due to the presence of the COVID-19 pandemic. The Government of Indonesia has instructed physical distancing so that teaching and learning activities, including in the Faculty of Medicine, must be carried out at home with online methods to reduce the risk of COVID-19 distribution. In response to the COVID-19 pandemic, most medical schools worldwide, including Indonesia, had started rapidly changing their learning methods from face-to-face to online delivery methods $[2,3]$

The COVID-19 pandemic pushes medical lecturer worldwide, including Indonesia, to shift their ways to continue providing high-quality medical education when the government applied large-scale social restriction. If we want to consider e-learning in a medical school curriculum, we must provide evidence- based research to encourage universities to implement this alternative learning method during the pandemic period ${ }^{[4,5]}$. Therefore, we conducted this study to explore the clerkship medical student's perspective toward the e-learning method during the COVID-19 pandemic period in the Department of Ophthalmology of the Faculty of Medicine Andalas University, Indonesia. This study will give an insight into the evaluation of e-learning in medical education. 


\section{METHODS}

This study was conducted from June to August 2020 at the Department of Ophthalmology of Faculty of Medicine Andalas University, Indonesia. This study design was a qualitative study. The online platform we used to conduct the e-learning was the iLearn platform of the Faculty of Medicine Andalas University. This study enrolled 64 clinical clerkship students who had been undergone "hands-on" and face-to-face clinical clerkship in the Department of Ophthalmology of Faculty of Medicine Andalas University, Indonesia, for four weeks. Another inclusion criteria were clinical clerkship students who still registered as medical students, clinical clerkship students who had iLearn platform personal account, and clinical clerkship students who participate in distance learning during the COVID-19 pandemic. Exclusion criteria were clinical clerkship students who not completed the fulfillment of both the quiz and the questionnaire. Another exclusion criterion was clinical clerkship students who already graduated from the Faculty of Medicine Andalas University.

In the first step of this study, the authors make four educational videos in basic knowledge and clinical skill in the ophthalmology field according to National Standard Competencies for General Practitioner. The four video topics include of:

- Topic 1: Visual acuity examination and introduction of ophthalmology examination tools. This video demonstrated step by step visual acuity examination procedure. This video also showed equipment and tools which usually used in clinical ophthalmology examination.

- Topic 2: History taking and subjective refractive examination. This video demonstrated step by step history taking in patient with refractive error and demonstrated refraction examination technique with a trial lens in simple myopia an astigmatism rule on a simulated patient.

- Topic 3: Case study of eyelid infection. This video demonstrated a hordeolum, which was an infection of the meibomian gland of the eyelid. The instructor showed history taking and physical examination on a real patient.

- Topic 4: Case study of conjunctival infection. This video demonstrated bacterial conjunctivitis. The instructor showed a slit-lamp photograph of the case with a physical examination result.

The videos uploaded to the iLearn platform, and the clinical clerkship students who participated in this study enrolled in the modules. After watching the educational videos, the clinical clerkship students were instructed to answer the quiz after each video session to know their comprehension about the video contents. Then, a questionnaire comprises of 10 questions where shared to the participant using social media platform. All data then collected and recorded computerized. The recorded data were then analyzed using the descriptive statistic method by calculating each statement's percentage in the questionnaire. The author then withdraws the conclusion from the study result.

\section{RESULTS}

The characteristics of the clinical clerkship students are following. Among 64 students, 52 were female $(81,25 \%)$ and 12 were male $(18,75 \%)$. The range of students ages was 19 years old to 28 years old with a mean age of 22,66 years old.

Assessment and evaluation of the e-learning method retrieved by quiz score. By assigning this type of assessment, we can know the clinical clerkship students' level of comprehension about educational content presented in the videos. Table 1 shows the mean score of the quiz by each topic, and Table 2 shows the grading of quiz scores.

Table 1. Mean score of each quiz topic.

\begin{tabular}{lc}
\hline Quiz & Mean score \\
\hline Topic 1 & 73,70 \\
Topic 2 & 54,23 \\
Topic 3 & 82,75 \\
Topic 4 & 80 \\
\hline
\end{tabular}

Table 2. Score grading of each quiz topic.

\begin{tabular}{lllll}
\hline \multirow{2}{*}{$\begin{array}{c}\text { Score } \\
\text { grade }\end{array}$} & \multicolumn{4}{c}{$\begin{array}{c}\text { Percentage of clinical clerkship students } \\
\text { in each quiz topic }\end{array}$} \\
\cline { 2 - 5 } & Topic 1 & Topic 2 & Topic 3 & Topic 4 \\
\hline Good & $24,07 \%$ & $1,9 \%$ & $41,17 \%$ & $37,25 \%$ \\
Average & $68,52 \%$ & $59,61 \%$ & $52,94 \%$ & $56,86 \%$ \\
Poor & $7,41 \%$ & $38,49 \%$ & $5,89 \%$ & $5,89 \%$ \\
\hline
\end{tabular}

The quiz assignment's purpose was to evaluate how much the students comprehend the educational content after watching the videos. For most of the topics, the students get good quiz scores that show that they can understand the video's content. An exception is for history taking and subjective refractive examination topic where the students get the low quiz score. This can be understood that even in face-to-face learning methods, subjective refractive examination is quite difficult to master by the clinical clerkship students. This examination needs patience and repetitive exercise so they can do it well and get an accurate measurement. Besides that, this examination needs a cooperative patient and does not enough by only watching an educational video. The students need to demonstrate it under the supervision of a senior ophthalmologist to get feedback after each session of the demonstration.

Table 3 shows the perception of the student about e-learning methods. Because they already experienced face-to-face learning methods before, they can compare the effectiveness of this e-learning to get essential competencies required 
Table 3. Perception of clinical clerkship students about Blended Learning.

\begin{tabular}{|c|c|c|c|c|c|c|}
\hline \multirow[b]{2}{*}{ No } & \multirow[b]{2}{*}{ Question } & \multicolumn{5}{|c|}{ Choiced answer of the question (\%) } \\
\hline & & $\begin{array}{l}\text { Strongly } \\
\text { disagree }\end{array}$ & Disagree & Neutral & Agree & $\begin{array}{c}\text { Strongly } \\
\text { agree }\end{array}$ \\
\hline 1. & The video was well prepared & - & $3,125 \%$ & $3,125 \%$ & $40,625 \%$ & $53,125 \%$ \\
\hline 2. & $\begin{array}{l}\text { Lecturer explaining and facilitates } \\
\text { learning activity with good method } \\
\text { through educational video }\end{array}$ & - & $3,125 \%$ & $1,56 \%$ & $39,06 \%$ & $56,25 \%$ \\
\hline 3. & $\begin{array}{l}\text { The topic presented was an } \\
\text { important topic for general } \\
\text { practitioner learned in clinical } \\
\text { practice }\end{array}$ & - & $4,687 \%$ & - & $25 \%$ & $70,31 \%$ \\
\hline 4. & $\begin{array}{l}\text { I get lot of knowledge by watching } \\
\text { the educational video }\end{array}$ & - & $4,687 \%$ & $3,125 \%$ & $37,5 \%$ & $54,69 \%$ \\
\hline 5. & $\begin{array}{l}\text { Delivery of content in educational } \\
\text { video was easily understand }\end{array}$ & - & $1,56 \%$ & $4,687 \%$ & $34,37 \%$ & $59,37 \%$ \\
\hline 6. & $\begin{array}{l}\text { Face to face learning was an } \\
\text { effective method for me to learn }\end{array}$ & - & $3,125 \%$ & $3,125 \%$ & $37,5 \%$ & $56,25 \%$ \\
\hline 7. & $\begin{array}{l}\text { Clinical skills was easier to } \\
\text { understand if demonstrated } \\
\text { directly by the instructure }\end{array}$ & - & $3,125 \%$ & $1,56 \%$ & $20,31 \%$ & $75 \%$ \\
\hline 8. & $\begin{array}{l}\text { Quiz assignment helps me to } \\
\text { comprehend the content in the } \\
\text { video }\end{array}$ & $1,56 \%$ & $3,125 \%$ & $4,687 \%$ & $51,56 \%$ & $40,625 \%$ \\
\hline 9. & $\begin{array}{l}\text { I understand the learning } \\
\text { objectives by watching the } \\
\text { educational video }\end{array}$ & $1,56 \%$ & $4,687 \%$ & $7,81 \%$ & $40,625 \%$ & $45,31 \%$ \\
\hline 10. & Overall, I satisfied with the quality & - & $4,687 \%$ & $9,375 \%$ & $39,06 \%$ & $46,87 \%$ \\
\hline
\end{tabular}
of e-learning through educational video presented

From the questionnaire, we can see in the study results, the majority of the students agree that the lecturer had well-prepared the educational video for online learning. Content delivery in the video is also well-understood by the student, and the educational video helps the student accomplish the learning objectives in clinical ophthalmology clerkship. However, some students argue that face-to-face learning methods were more effective than e-learning methods, especially to train their clinical skills with direct supervision by the senior ophthalmologist. A clinical skill which directly demonstrated by the instructor will be easier to understand and perform according to the majority of the students.

\section{DISCUSSION}

The spread of COVID-19 has led most countries worldwide to implement emergency lockdown plans and apply social distancing strategies to limit the virus' spread; this has resulted in the interruption of school and university attendance. The responses to the COVID-19 pandemic by medical schools worldwide have varied, from total study cessation to

a switch to online/distance learning. This sudden transition to distance learning approaches from oncampus learning is challenging for both faculty and students and has required much planning over a short period and without any clear guidelines ${ }^{[6,7]}$.

Previously the pandemic period, a clinical clerkship in the Department of Ophthalmology, comprised four weeks. The learning program includes bedside teaching, case report sessions, clinical science sessions, and meeting the expert. Bedside teaching and case report sessions involve the real patient and hands- on examinations, while clinical science sessions and meets the expert only a scientific discussion. COVID- 19 pandemic had transformed our learning program in clinical clerkship, which comprises two weeks of online learning and two weeks of observership. In the online learning period, the students enrolled in iLearn platform and were assigned to watch educational videos, complete the quiz, and make a case presentation. In the observership period, the students came to the teaching hospital wearing personal protective equipment, which is mandatory. The students can observe the real patient examination 
directly in the outpatient clinic. Afterward, the supervisor gives an explanation and discussion about the patient examined before. So we combined the online and face-to-face learning method, which is called blended learning.

Blended learning, where online learning is combined with traditional face-to-face teaching, is likely to capture more students' learning styles and is often associated with an increased need for selfdirected learning, which may benefit high-achieving students. Blended learning is both simple and complex. Simultaneously, blended learning is the thoughtful integration of classroom face-to-face learning experiences with online learning experiences. There is a considerable intuitive appeal to the concept of integrating the strengths of synchronous (face-to-face) and asynchronous (textbased Internet) learning activities. Simultaneously, there is considerable complexity in its implementation with the challenge of virtually limitless design possibilities and applicability to so many contexts ${ }^{[8,9]}$.

Ease of access to educational materials and the ability to choose the time and place to study were shown as the most substantial advantages of online learning. Remote access is of particular importance during the COVID-19 pandemic, but it can also reduce accommodation and transportation costs in other settings. E-learning enables learning materials to be quickly delivered to students, standardized, and, if needed, updated. Content can be delivered to students using two different approaches: self-directed and instructor-led learning. Self-directed e-learning allows the learner to manage his activity independently ${ }^{[10-12]}$. In this study, most students stated that they could understand their learning objective through online learning.

E-learning is not without its disadvantages. The main problem for the students in this study was the lack of interaction with patients. Learning from real patients in a clinical setting is crucial for medical education, and it cannot be fully replaced with distance learning. To some extent, a solution to this issue could be the use of simulated patients. Simulated patients are designed to simulate real-life clinical scenarios, and they enable the learner to prepare him/herself before a real patient encounter. The instructor demonstrated the clinical skill with the virtual patients, and these activities is recorded by video. The video can be uploaded to online learning platform, and the students can watch the video repeatedly until they can fully understand how the steps to perform the clinical skill. By the time the students can get back to conventional face-to-face learning, they can practice the clinical skill they have learned before with online learning ${ }^{[13-15]}$. In this study, most students argue that face-to-face method was more effective than online learning, especially in complicated clinical skills such as subjective refractive examination. So, the observership learning program with face-to-face methods was still important and needed for medical students to experience clinical examination with real patients.

Overall, the student's perception was good about blended learning, and the topic presented in elearning was an essential topic to learned and very useful in clinical practice as a general practitioner. The topic presented in the educational video was chosen to meet the National standard of competencies, where the students should have established the diagnosis of a disease and managed the treatment until resolution of the disease. Finally, this study's limitations include the relatively short period in which the students have experienced eLearning first-hand. This study also does not compare the e-learning method's outcome with the conventional face-to-face method. However, with reasonable satisfaction from most students in this study, we hope that e-learning can complement faceto-face learning, especially in this pandemic period.

\section{CONCLUSION}

This study results can encourage that a blended learning model, which incorporates video- assisted online resources, can be useful for acquiring clinical skills by health students. Flexibility to time and place was the most critical advantage of e-Learning, and lacking to perform essential clinical skills was the primary concern. Quality assurance of the blended learning video resource should be done to enable students to understand the context and engage with video resources, so in time they encounter real patients, they are already prepared and gain sufficient competencies.

\section{ACKNOWLEDGMENT}

This work was supported by the grant from the quality assurance and education institutions of Andalas University.

\section{REFERENCES}

[1] Cecilio Fernandes D, Parisi M, Santos T, Sandars J. The COVID-19 pandemic and the challenge of using technology for medical education in low and middle income countries. MedEdPublish. 2020;9.

[2] Utama MR, Levani Y, Rumkhullah E, Paramita AL. Medical students perspectives about distance learning during the early period of COVID-19 pandemic: A qualitative study. Qanun Medika. 2020;4(2):255-64.

[3] Rajab H, Gazal A, Alkattan K. Challenges to Online Medical Education During the COVID19 Pandemic. Cureus. 2020;12. 
[4] Ali S, Afreni H. Pembelajaran Daring di Tengah Wabah Covid-19. BIODIK. 2020;6(2).

[5] Samaraskera D, Goh D, Yeo S, Ngiam N, Aw M, Lim M, et al. Response and Lessons Learnt Managing the COVID-19 Crisis by School of Medicine, National University of Singapore. MedEdPublish. 2020;9.

[6] Alqudah NM, Jammal HM, Saleh O, Khader Y, Obeidat N, Alqudah J. Perception and experience of academic Jordanian ophthalmologists with E- Learning for undergraduate course during the COVID-19 pandemic. Annals of Medicine and Surgery. 2020;59:44-7.

[7] Taha M, Abdalla ME, Wadi M, Khalafalla H. Curriculum delivery in Medical Education during an emergency: A guide based on the responses to the COVID-19 pandemic. MedEdPublish. 2020;9.

[8] Garrison DR, Kanuka H. Blended learning: Uncovering its transformative potential in higher education. The Internet and Higher Education. 2004;7(2):95-105.

[9] Kirk LE, Mitchell I. The impact of the COVID19 pandemic on medical education. Medical Journal of Australia.n/a(n/a).

[10] Moszkowicz D, Duboc H, Dubertret C, Roux D, Bretagnol F. Daily medical education for confined students during coronavirus disease 2019 pandemic: A simple videoconference solution. Clinical Anatomy. 2020;33(6):927-8.

[11] Rajab MH, Gazal AM, Alkattan K. Challenges to Online Medical Education During the COVID-19 Pandemic. Cureus. 2020;12(7):e8966-e.

[12] Ilic D, Nordin RB, Glasziou P, Tilson JK, Villanueva E. A randomised controlled trial of a blended learning education intervention for teaching evidence-based medicine. BMC Med Educ. 2015;15:39.

[13] Lehmann R, Bosse HM, Simon A, Nikendei C, Huwendiek S. An innovative blended learning approach using virtual patients as preparation for skills laboratory training: perceptions of students and tutors. BMC Medical Education. 2013;13(1):23.

[14] Coyne E, Rands H, Frommolt V, Kain V, Plugge $M$, Mitchell $M$. Investigation of blended learning video resources to teach health students clinical skills: An integrative review. Nurse education today. 2018;63:101-7.

[15] T F, D J, G A. Challenging assumptions about "moving online" in response to COVID-19, and some practical advice. MedEdPublish. 2020;9(1):83. 